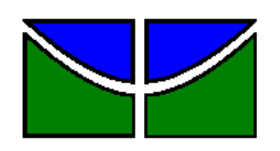

Universidade de Brasília

Faculdade de Economia, Administração, Contabilidade e Ciências da Informação e Documentação Departamento de Administração

ANA ELOIZA CASARÔTO GOULART

\title{
O IMPACTO DO TREINAMENTO NA TUTORIA NO ENSINO A DISTÂNCIA
}

Brasília - DF 


\title{
ANA ELOIZA CASARÔTO GOULART
}

\section{O IMPACTO DO TREINAMENTO NA TUTORIA NO ENSINO A DISTÂNCIA}

Projeto de monografia apresentado ao Departamento de Administração como requisito parcial à obtenção do título de Bacharel em Administração, na modalidade à distância, pela Universidade de Brasília (UnB).

\author{
Professor Supervisor: Doutora Juliana Porto \\ Professor Tutor: Mestre Alexandre Domanico da Cunha
}

\author{
Brasília - DF \\ 2010
}




\section{SUMÁRIO}

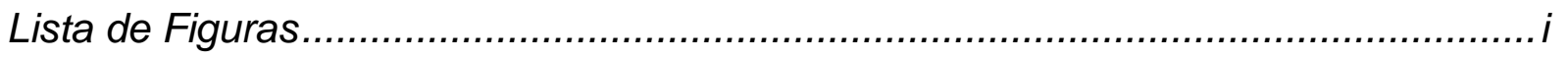

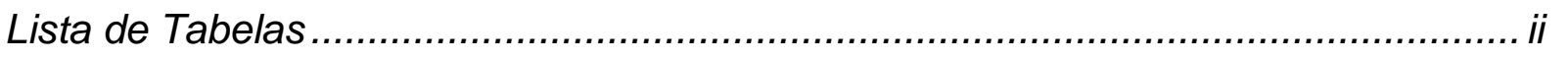

$1 \quad$ INTRODUCCÃO

1.1 Formulação do problema...............................................................................

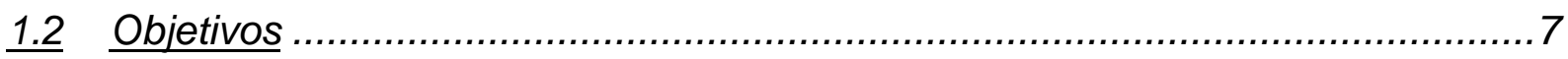

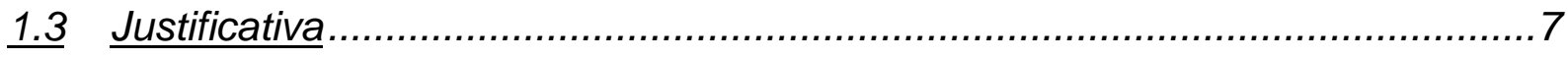

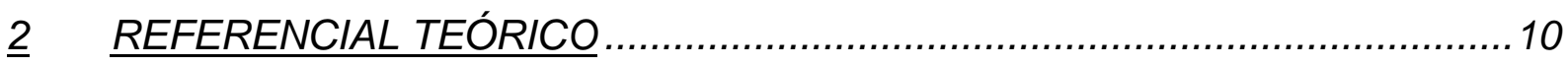

2.1 O Ensino à Distância ........................................................................... 10

2.2 A Tutoria

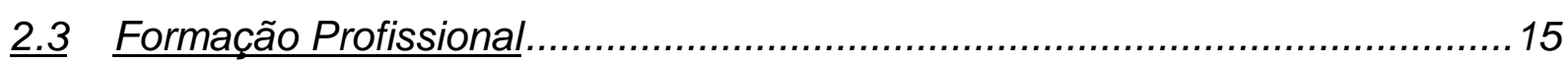

3 MÉTODOS E TÉCNICAS DE PESQUISA................................................18

3.1 Tipo e descrição geral da pesquisa........................................................18

3.2 Caracterização da organização ...........................................................18

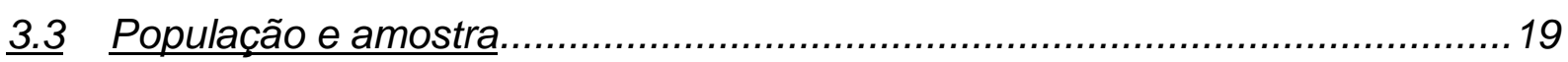

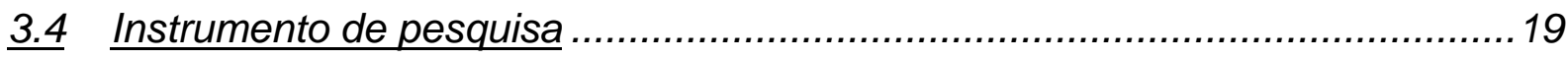

3.5 Procedimentos de coleta e de análise de dados ...........................................20

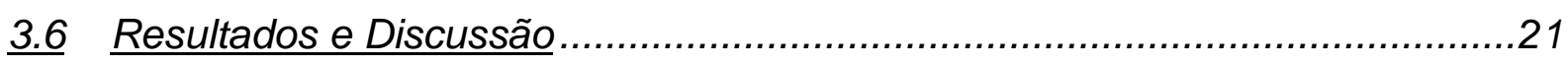

CONCLUSÃO

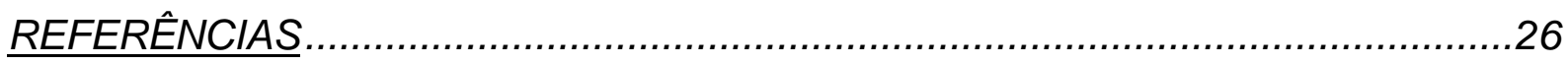

ANEXOS

Questionário de Avaliação de Reação do aluno ao Tutor ......................................28 


\section{LISTA DE FIGURAS}

Gráfico 1: Instituições de Ensino à Distância de 2002 a 2008 8

Gráfico 2: Cursos de Graduação de 2002 a 2008. .8 


\section{LISTA DE TABELAS}

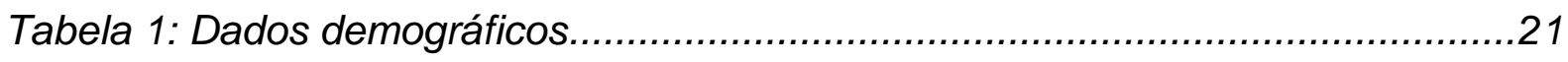

Tabela 2: Desempenho dos tutores por fatores/média por turma .........................22

Tabela 3: Nota média por tutor/fator avaliado ...............................................23 


\section{INTRODUÇÃO}

A Educação desempenha papel fundamental na vida do homem, sendo uma estratégia da formação humana, mediante a qual o indivíduo forma suas qualidades humanas, físicas, morais, intelectuais e estéticas (LIBÂNEO, 1990).

São três as concepções filosófico-políticas da educação: concepção redentora, reprodutiva e transformadora.

A primeira concepção, a redentora, objetiva formar as habilidades e os valores éticos segundo a necessidade de manutenção da vida em sociedade, sendo responsável pela adaptação do indivíduo à mesma, não compreendendo criticamente o fenômeno educativo (LUCKES, 1990)

A concepção reprodutiva compreende a educação como um fenômeno histórico-social, fruto das condições culturais, econômicas e políticas, portanto reprodutora ideologicamente destas mesmas condições (LUCKES, 1990)

No sentido social a educação conduz o indivíduo a participar de um grupo sócio-cultural na medida em que repassa a ele os valores e normas de determinada região, capacitando-o a ser co-participante da construção da sociedade (LUCKES, 1990).

$\mathrm{Na}$ terceira e última concepção encontra-se uma interpretação da educação dimensionada nos determinantes sociais como uma possibilidade de agir criticamente, sendo utilizada na transformação social (LUCKES, 1990).

Cada sociedade desenvolve um sistema de educação que se impõe aos indivíduos, direcionando o desenvolvimento de cada um. Esse direcionamento variará de acordo com o grupo e o interesse social (SOUZA, 2000).

Essas três vertentes educativas indicam diferentes maneiras de olhar para um projeto educativo: um redentor, um reprodutivo e um transformador. 
Utilizando oportunamente a vertente reprodutiva, a educação como resultado do momento histórico da sociedade, dois grandes acontecimentos sociais a industrialização e o desenvolvimento tecnológico, incidiram em todos os setores, mormente o educativo.

Neste, como uma conseqüência da industrialização e sua forma de produção em massa e da qualificação da mão de obra, trouxe consigo a necessidade de uma educação mais ampla no sentido de propiciar oportunidades para um maior número de trabalhadores.

A educação ao longo da vida será crucial para a competitividade do indivíduo no mercado de trabalho, assegurando igualdade de oportunidades, e para a competitividade do país, que necessita de recursos humanos cada vez mais qualificados (LJOSÃ, 1992).

As inovações tecnológicas, mormente a internet, propiciaram ao estudante inúmeras oportunidades de desenvolvimento, tais como: sanar dúvidas de conteúdo, trocar idéias com outros estudantes, pesquisas para trabalho etc.

Propiciou ainda um novo impulso na Educação à Distância. De início realizada por trens ou correio (PETERS, 1983) num processo individual de ensinoaprendizagem, a Educação à Distância realizada pela internet tem como vantagem primordial levar o acesso ao conhecimento a um maior número de pessoas, formando indivíduos independentes e autônomos.

Se de um lado o ensino a distância produz vantagens significativas ao aluno, por outro lado o papel do professor torna-se segmentado, produzindo três funções distintas.

A primeira função conduz à responsabilidade pela concepção e realização dos cursos e materiais; o segundo assegura o planejamento e organização da distribuição de materiais e da administração acadêmica; e o terceiro cuida do estudante no processo de aprendizagem, acompanhando as atividades discentes, 
motivando a aprendizagem, orientando e proporcionando ao aluno condições de uma aprendizagem autônoma.

Este último é conhecido no meio acadêmico como tutor. O tutor atua como mediador, facilitador, incentivador, investigador do conhecimento, da própria prática e da aprendizagem individual e grupal (ALMEIDA, 2001).

Hanna (apud Alves; Nova, 2003:37) apresenta algumas sugestões para o professor que deseja atuar como tutor em algum curso a distância. Sugere que ele deve:

- conhecer sua fundamentação pedagógica;

- determinar sua filosofia de ensino e aprendizagem;

- ser parte de uma equipe de trabalho com diversas especialidades;

- desenvolver habilidades para o ensino online;

- conhecer seus aprendizes;

- conhecer o ambiente online;

- aprender sobre os recursos tecnológicos;

- criar múltiplos espaços de trabalho, de interação e socialização;

- estabelecer o tamanho de classe desejável;

- criar relacionamentos pessoais online;

- desenvolver comunidades de aprendizagem;

- definir as regras vigentes para as aulas online; e

- esclarecer suas expectativas sobre os papéis dos aprendizes.

"O tutor se encontra diante de uma tarefa desafiadora e complexa" (LITWIN, 2001:103). O bom desempenho desses profissionais repousa sobre a crença de que "só ensina quem aprende", o alicerce do construtivismo pedagógico (GROSSI; BORDIN, 1992). 


\subsection{Formulação do problema}

Tendo em vista a importância do tutor no processo de ensino-aprendizagem na Educação à Distância, essa pesquisa tem por objetivo responder a seguinte questão: $\mathrm{O}$ treinamento específico da tutoria em $\mathrm{aD}$ via internet é necessário para o exercício da tutoria?

\subsection{Objetivos}

O objetivo geral deste trabalho é identificar se o treinamento específico em tutoria é determinante no desempenho dos tutores no ensino à distância via internet.

Os objetivos específicos são:

- Coletar informações do aluno quanto à tutoria;

- Analisar a reação do aluno quanto à tutoria;

- Verificar o desempenho do tutor com o curso de tutoria;

- Verificar o desempenho do tutor sem o curso de tutoria.

\subsection{Justificativa}

As instituições e cursos com propostas de EaD multiplicam-se. Segundo dados do Estudo Setorial elaborado pela All Consulting, dados do MEC, o número de instituições de Ensino à Distância no segmento de ensino superior em 2008 era de 115 contra apenas 25 em 2002. O número de cursos de graduação oferecidos em 2008 era de 647 contra 52 em 2003. 

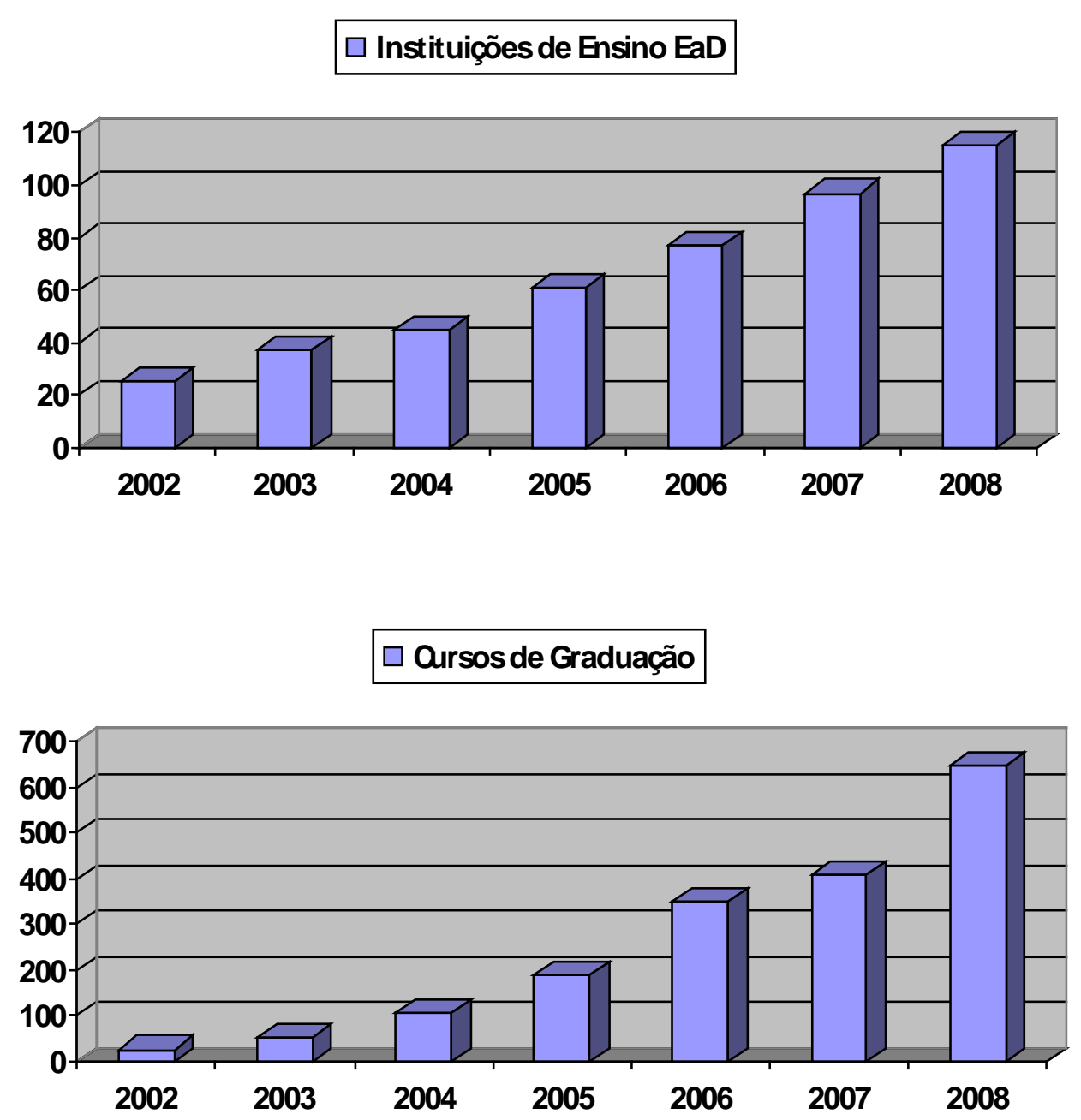

$\mathrm{Na}$ maioria das primeiras experiências em EaD registradas a ênfase era dada nas funções de concepção e realização dos cursos e materiais e planejamento e organização da distribuição de materiais e da administração acadêmica.

Somente a partir da última década aumentou a preocupação com 0 estudante e, com isso, ocorreu o crescimento dos investimentos em atividades de tutoria (Belloni, 1999).

A função de acompanhamento do estudante durante 0 processo de aprendizagem é fundamentalmente para os objetivos das instituições que trabalham com a modalidade de educação a distância.

Assim, o presente trabalho pretende apresentar sua contribuição para os acadêmicos e estudiosos com embasamento teórico, oferecendo material 
informativo, cuja credibilidade proporcione fonte de consulta sobre o importância da função de tutoria em EaD à Distância via internet.

O trabalho está estruturado em duas seções. A primeira seção abrange uma revisão bibliográfica do Ensino à Distância, da Tutoria em EaD e da Formação Profissional. Ao final da primeira seção é apresentado o curso de Tutoria desenvolvido pelo Sebrae.

A segunda seção compreende a pesquisa de campo realizada na Uab/Unb, tratada em cinco tópicos: 1. Tipo e descrição geral da pesquisa, 2. Caracterização da organização, 3. População e amostra, 4. Instrumento de pesquisa e 5. Procedimentos de coleta e de análise de dados. 


\section{REFERENCIAL TEÓRICO}

Nos tópicos que se seguem serão abordados o Ensino a Distância, o papel da tutoria no Ensino à Distância via internet e a Formação Profissional. Em seguida será apresentada a pesquisa realizada com as turmas da disciplina Tópicos Emergentes - Redes do curso de Administração da UaB/Unb, 9º semestre.

\subsection{O Ensino à Distância}

A revolução industrial trouxe significativas mudanças econômicas e sociais. No campo da educação provocou aumento na demanda diante do tipo de produção em massa e da necessidade dos trabalhadores qualificarem-se.

Com o surgimento da internet e o desenvolvimento tecnológico, o Ensino a Distancia até então realizado por correspondência via correio, rádio, televisão, vídeo, CD-ROM, telefone e outras tecnologias, ganha novo impulso ampliando as oportunidades de ensino e possibilitando a democratização da educação.

A Educação à Distância é um sistema tecnológico de comunicação de massa e bidirecional, que substitui a interação pessoal na sala de aula de professor e aluno, como meio preferencial de ensino, pela ação sistemática e conjunta de diversos recursos didáticos e apoio de uma organização e tutoria que propiciam uma aprendizagem independente e flexível, (ARETIO, 1996).

Suas vantagens, segundo Diaz Bordenave (1988) são:

- Pode alcançar um grande número de pessoas e grupos, mesmo que as distâncias físicas e sociais entre os indivíduos sejam enormes;

- Facilita a aprendizagem das pessoas, permitindo o uso do tempo disponível, sem a necessidade de se locomoverem do lar ou do local de trabalho;

- Adapta-se ao ritmo próprio de aprendizagem de cada indivíduo, podendo ser realizada em grupos ou individualmente; 
- Reduz o custo de capacitação por estudante, além de economizar com as despesas pessoais do aluno tais como transporte e alimentação;

- Requer poucos instrumentos para elaborar os conteúdos e materiais didáticos: material impresso, vídeos, televisivo e radiofônicos, videoconferências, CD-Rom, páginas WEB e outros, atendendo a diferentes lógicas de concepção, produção, linguagem estudo e controle de tempo, permitindo a contratação dos melhores especialistas em cada área do conhecimento;

- Serve, pela versatilidade da metodologia, tanto à educação formal quanto à informal;

- Desenvolve a capacidade do autodidatismo (aprender sem a presença do professor.

Para a obtenção de qualidade na educação à distância, Gouveia e Bizzo em Parecer à Câmara de Educação Básica do Conselho Nacional de Educação (2002, p. 10) definem como pressupostos básicos à educação a distância de qualidade:

- Relação professor-aluno - a separação professor-aluno ocorre em diferentes níveis, do estudo individual isolado à assistência de sistemas organizados de recepção. O aluno, porém, nunca deve sentir-se só. É necessário prever esquemas de acompanhamento, instâncias às quais recorrerem, sejam dos próprios instrutores, face a face, ou através de meios eletrônicos

- Existência de uma instituição responsável - cabe às instituições a responsabilidade de formar e manter a equipe encarregada do tratamento dos currículos, pelo planejamento e elaboração dos materiais de instrução, pela implementação e pela implantação dos cursos e programas. É preciso ficar claro que as atividades envolvidas na educação à distância constituem trabalho de equipes interdisciplinares (pedagogo, especialista em conteúdo, especialista em comunicação audiovisual, técnicos: redatores, ilustradores, produtores de televisão, de rádio, programadores e outros).

- Utilização de meios de comunicação - a educação a distância utiliza diferentes "mídias" de comunicação para estabelecer contato com seus alunos. A escolha do meio, ou de uma combinação de meios, depende do tipo de conteúdo que está sendo tratado; da abrangência do projeto; da população 
a ser atingida, da amplitude da área geográfica, das condições sócioeconômicas; da experiência de vida e das habilidades dos alunos; dos recursos financeiros disponíveis para a execução do projeto; das condições de recepção dos alunos; do conhecimento da linguagem de cada meio. A integração de vários meios oferece maior cobertura para as diferenças individuais e maior riqueza de informações.

- Tratamento e apresentação dos conteúdos - no que se referem ao material didático, os textos devem ser trabalhados para esclarecer os objetivos a atingir, motivar o aluno, dialogar com ele, facilitar sua aprendizagem, em linguagem clara e simples. O material didático deve ser preparado por uma equipe multidisciplinar, composta pelos melhores especialistas nos conteúdos a serem trabalhados, que tenham acesso à bibliografia própria e atualizada e às mais rica fontes de informação. Isto viabiliza a elaboração de materiais de boa qualidade, capazes de incrementar as aulas presenciais dos melhores professores.

- Implementação de formas de comunicação professor/aluno - ou instituição educacional - os diferentes níveis de presencialidade introduzem no sistema um personagem novo, conhecido por tutor. Sua função é atender o aluno em suas dificuldades, motivá-lo, orientar suas atividades, supervisionar suas tarefas. É também o orientador de aprendizagem responsável pela avaliação do progresso dos alunos. A capacitação dos mesmos é indispensável para o êxito dos programas.

- Avaliação no processo permitindo ao aluno acompanhar seu próprio desenvolvimento - A avaliação realizada ao longo do processo de ensino aprendizagem permite colher informações que possibilitam reformular, corrigir ou recuperar eventuais falhas do processo, do programa ou do material, aperfeiçoando-os. Importância especial é atribuída na educação à distância à validação do material didático produzido. Este procedimento o é adotado para verificar se os elementos propostos no planejamento do material didático apresentam-se de forma adequada no produto e se os resultados obtidos com a sua aplicação correspondem às expectativas.

As funções dos docentes, que no ensino presencial são asseguradas por um indivíduo, tornam-se fragmentadas desdobrando-se em três grandes grupos: o 
primeiro é responsável pela concepção e realização dos cursos e materiais; o segundo assegura o planejamento e organização da distribuição de materiais e da administração acadêmica; e o terceiro responsabiliza-se pelo acompanhamento do estudante durante $\mathrm{o}$ processo de aprendizagem (tutorias, aconselhamento e avaliação), (BELLONI, 1999).

Este último grupo, conforme Corrêa (2004) implica necessariamente investir na organização e no desenvolvimento do trabalho de tutoria.

\subsection{A Tutoria}

Gonçalves, (2007) define "Tutoria" como o conjunto de ações educativas que contribuem para desenvolver e potencializar as capacidades básicas dos acadêmicos, orientando-os, dirigindo-os, motivando-os, avaliando-os para que obtenham crescimento intelectual e autonomia, ajudando-os a tomar decisões em vista de seus desempenhos e participações como acadêmicos.

A tarefa do tutor "consiste em assegurar o cumprimento dos objetivos, servindo de apoio ao programa" (LITWIN, 2001), auxiliando na realização das atividades e apoiando suas resoluções. É por intermédio dele, também, que se garantirá a efetivação do curso em todos os níveis (PRETI, 1996).

Aretio, 2002 ao ter uma visão geral sobre o trabalho de tutoria afirma que o tutor deve possuir algumas qualidades, como: autenticidade e honradez, maturidade emocional, bom caráter e cordialidade, compreensão de si mesmo, capacidade empática, inteligência e agilidade mental, capacidade de escutar, cultura social, estabilidade emocional, capacidade de aceitação, inquietude cultural e amplos interesses, liderança, entre outras.

Assim, o sucesso da EaD está diretamente relacionado com o desempenho dos tutores (CORTELAZZO, 2005) e o desempenho de suas funções está ligada as . 
Dentre as competências citam-se: cultura técnica (conhecimento mínimo das novas tecnologias); competências de comunicação (pelo trabalho em equipe que será necessário); capacidade de trabalhar com método (sistematizar e formalizar procedimentos e métodos); capacidade de "capitalizar" (aproveitar conhecimentos já construídos e disponibilizar os próprios conhecimentos) Blandin (1990, apud Belloni, 1999).

Para garantir a desenvolvimento destas competências é indispensável que as instituições desenvolvam planos de capacitação de seu corpo de tutores. Um programa de capacitação de tutores deve, no mínimo, prever três dimensões (MEC, 2007):

- capacitação no domínio específico do conteúdo;

- capacitação em mídias de comunicação; e

- capacitação em fundamentos da EaD e no modelo de tutoria.

Para ser possível ao tutor a aquisição e ou o desempenho das competências torna necessário o treinamento.

Naethe (1992), ao analisar a queda de qualidade dos processos educacionais, afirma que as pessoas que são colocadas no mercado de trabalho irão necessitar de complementação curricular e que, com isso o treinamento e retreinar; capacitar para a execução de novas tecnologias; desenvolver novos padrões de mentalidade para a qualidade, entre outros desafios.

A formação de professores não escapa a esta lei: estes devem como o restante da sociedade, levar em consideração a inovação: mas esta deve ser preparada por uma formação adequada. (...) Todo o pessoal docente deve aceitar evoluir como as outras profissões (DIEUZEIDE, 1994: p.200). 


\subsection{Formação Profissional}

Sousa e colaboradores (1999) consideram a educação vinculada diretamente à ascensão social, ou seja, quanto maior a escolaridade maior a empregabilidade, existindo, por conseguinte, uma relação inversa entre a formação profissional e o desemprego.

Segundo Aranha (2001), por empregabilidade entende-se a responsabilização do trabalhador pela obtenção e manutenção do seu emprego, por meio de um processo contínuo de formação e aperfeiçoamento.

No entendimento de Cattani (2002) a formação profissional são todos os processos educativos que permitem ao indivíduo adquirir e desenvolver conhecimentos teóricos, técnicos e operacionais relacionados à produção de bens e serviços.

A formação profissional é uma estratégia em busca de qualidade e produtividade, estando próxima aos conceitos de treinamento e desenvolvimento que na concepção de Vargas (1996) representam a aquisição sistemática de conhecimentos capazes de provocar uma mudança de ser e de pensar do indivíduo, por meio da internalização de novos conceitos, valores ou normas e da aprendizagem de novas habilidades.

Bastos (1991) afirma que desenvolvimento de recursos humanos é um conceito global, envolvendo, além de outras funções, a de treinamento. Igualmente, Sallorenzo (2000) define desenvolvimento como um processo de aprendizagem mais geral, porque propicia o amadurecimento de indivíduos de forma mais ampla, não específica para um posto de trabalho.

Enquanto desenvolvimento é tido pela maioria dos autores como um processo amplo de aprendizagem, treinamento é definido como a aquisição sistemática de atitudes, conceitos, conhecimentos, regras e habilidades que resultam em uma melhoria do desempenho no trabalho (GOLDSTEIN, 1991). 
Para as organizações e aqui também para a sociedade, devido ao papel da tutoria no ensino EaD, o treinamento tem importância na medida em que cria atitudes e comportamentos positivos para os objetivos organizacionais e dos indivíduos.

O treinamento tem como proposta a identificação e superação de deficiências no desempenho dos profissionais, assim como a preparação para novas funções e ao retreinamento para adaptação da mão-de-obra à introdução de novas tecnologias no trabalho, indo de encontra às necessidades do profissional de tutoria EaD.

Para Rosenberg (2001) o treinamento apresenta quatro elementos principais:

- A intenção de melhorar um desempenho específico, normalmente derivado de uma avaliação de necessidades e refletido na elaboração de objetivos instrucionais;

- O desenho que reflete a estratégia instrucional que melhor se ajusta à aprendizagem requerida e às características da clientela, bem como às estratégias de mensuração que apontam a eficácia do treinamento;

- Os meios pelos quais a instrução é entregue, que pode incluir a sala de aula, uma variedade de tecnologias, estudos independentes ou a combinação de diferentes abordagens;

- A avaliação, cujos níveis de complexidade podem variar desde situações mais simples até as mais formais que incluam exigência de certificação.

O Treinamento e o Desenvolvimento formam um sistema integrado por três elementos: a) avaliação de necessidades; b) planejamento do treinamento e sua execução e c) avaliação do treinamento.

Este último, a avaliação, é o processo pelo qual se emiti um juízo de valor a respeito do treinamento, tendo como função o provimento de informações que garante a retroalimentação do sistema de treinamento. 
A avaliação do treinamento deve seguir cinco níveis, segundo Hamblin (1978):

- Reação - levantamento de opiniões e atitudes dos treinamendo sobre o treinamento;

- Aprendizagem - verificação de aprendizagem dos treinandos e alcance dos objetos instrucionais;

- Comportamento no cargo - verificação de transferência de aprendizagem para o trabaho;

- Organização - verifica se houve mudança na organização em decorrência do treinamento;

- Valor Final-compara os custos dos treinamentos com os seus benefícios.

No caso especifico da tutoria, existem diversos modelos de treinamento, cada instituição que desenvolve EaD constrói seu modelo tutorial. 


\section{MÉTOdOS E TÉCNICAS DE PESQUISA}

Segundo a definição de Ferreira (1986, p.1320), pesquisar significa uma busca minuciosa para averiguação da realidade ou ainda, investigação e estudo com o fim de descobrir ou estabelecer fatos ou princípios relativos a um campo qualquer do conhecimento.

Dentro desta perspectiva e embasados na classificação de Mattar (1999) quanto a variáveis de Vergara (2000, p.46), identificou-se quanto os meios de investigação, a pesquisa como sendo: bibliográfica e de campo.

\subsection{Tipo e descrição geral da pesquisa}

A pesquisa será Bibliográfica porque para o embasamento teórico do trabalho foi realizada uma investigação sobre os seguintes assuntos: educação, formação profissional, ensino à distância e tutoria no ensino à distância.

E de campo com a aplicação de dois questionários estruturados como instrumentos para coleta de dados. O primeiro aplicado em sala de aula e o segundo encaminhado via emails. Os questionários serão apresentados a seguir.

\subsection{Caracterização da organização}

A pesquisa será realizada com os alunos do Centro de Educação a Distância da Universidade de Brasília - CEAD/UnB - órgão da estrutura da Universidade de Brasília, tendo como função disseminação do conhecimento.

Atuando desde 1979, o CEAD busca por meio da educação a distância superar obstáculos da distância física e temporal, facilitando o acesso à educação 
através de variadas ferramentas de interatividade e recursos com a utilização do software Moodle.

O CEAD é composto organizacionalmente pelas Coordenações Acadêmicas e Executivas, pelas Unidades de Tecnologia, Pedagogia, Produção e Apoio Acadêmico e com as áreas de Comunicação, Gestão de Pessoas, Logística e Setor Financeiro.

Tem como infra-estrutura sua sede e salas de informática localizadas no Campus Universitário Darcy Ribeiro e utilizadas no desenvolvimento das atividades de tutoria e treinamento.

\subsection{População e amostra}

A população participante desta pesquisa foram as 16 turmas do 9ำ semestre do curso de administração à distância da UaB/Unb que estavam cursando a disciplina Tópicos Emergentes - Redes, compreendendo aproximadamente 250 alunos.

Das 16 turmas que participariam inicialmente, 11 turmas entregaram 0 questionário de reação ao desempenho do tutor. Dessas 11 turmas apenas 8 responderam aos dados demográficos solicitados posteriormente a aplicação do questionário, via email.

Assim, a amostra da pesquisa foi 8 turmas da disciplina Tópicos Emergentes - Redes ou 129 alunos.

\subsection{Instrumento de pesquisa}

O instrumento de pesquisa visa avaliar a percepção dos participantes sobre o desempenho do tutor. Trata-se de um questionário desenvolvido pelo trabalho de 
dissertação apresentada ao Instituto de Psicologia da Universidade de Brasília como requisito para a obtenção do grau de Mestre em Ciências - Psicologia de Thaís Zerbini.

Inicialmente o questionário continha 44 itens, contudo após realizada uma análise para redução do número de itens e aprimoramento de sua redação, conforme sugeriu a própria autora em seu estudo, ficaram definidos 28 itens.

Esta nova configuração foi definida no trabalho de dissertação apresentado ao Instituto da Universidade de Brasília como requisito para o obtenção do grau de mestre em Ciências - Psicologia de Maria Fernanda Borges Ferreira.

O questionário contendo 28 itens é aplicado a uma escala de freqüência, de 11 pontos, do tipo Likert, em que 0 (zero) corresponde a Nunca e 10 a Sempre (Anexo 4).

Estes 28 itens estão agrupados há três fatores divididos conforme abaixo:

$>$ itens de 1 a 8 e item 12 - estratégias motivacionais;

$>$ itens 10 e 11 - respeito aos alunos;

> item 9 e itens de 12 a 28 - desempenho didático e domínio do conteúdo.

\subsection{Procedimentos de coleta e de análise de dados}

O instrumento de pesquisa foi aplicado após autorização prévia da CEAD/UNB no último encontro do $9^{\circ}$ semestre das turmas do curso de Administração da disciplina Tópicos Emergentes - Redes, em Dezembro/2010, data em que foi aplicada a prova de avaliação da referida matéria.

Os questionários foram entregues aos 16 tutores da disciplina Tópicos Emergentes - Redes e distribuídos aos alunos simultaneamente às provas. Dos 16 tutores apenas 11 recolheram os questionários ao término da prova, os demais esqueceram. 
Destas 11 turmas que entregaram o questionário apenas 8 responderam os dados demográficos solicitados via email aos alunos.

\subsection{Resultados e Discussão}

Depois de recebidos os dados demográficos dos participantes da pesquisa, via email, ao todo 129 alunos distribuídos entre as turmas A, B, C2, D, E, G, K e I2, os resultados estão resumidos na tabela 3 a seguir:

Tabela 1 - Dados Demográficos.

\begin{tabular}{|c|c|c|c|c|c|c|c|}
\hline Sexo & $\%$ & Idade & $\%$ & Instrução & $\%$ & Residência & $\%$ \\
\hline 82 homens & $63,57 \%$ & 20 a $29-31$ & $24,03 \%$ & 2 doutorado & $1,55 \%$ & DF -117 & $90,70 \%$ \\
\hline 47 mulheres & $36,43 \%$ & 30 a $39-51$ & $39,53 \%$ & 3 mestrado & $2,33 \%$ & G0 -5 & $3,88 \%$ \\
\hline & & 40 a $49-30$ & $23,26 \%$ & 20 pós grad. & $15,50 \%$ & MG -3 & $2,33 \%$ \\
\hline & 50 a $59-16$ & $12,40 \%$ & 37 superior & $28,68 \%$ & Outros -4 & $3,10 \%$ \\
\hline & 60 a $69-1$ & $0,78 \%$ & 672 grau & $51,94 \%$ & & \\
\hline
\end{tabular}

De acordo com a tabela $63,57 \%$ dos alunos são homens, 63,56\% têm menos de 40 anos, quase 50\% possuem curso superior e 90,70\% residem no Distrito Federal.

Dos 129 alunos que receberam o questionário, 107 alunos o responderam e o entregaram. A tabela 3 fornece o resultado da avaliação dos tutores em relação aos fatores avaliados: 1. Estratégias motivacionais; 2. Respeito aos alunos e 3. Desempenho didático e Domínio do conteúdo.

Para montar a tabela 3 foram somadas as notas dos alunos por turma para cada um dos 28 itens avaliados, verificando em seguida o percentual de cada nota em relação ao total de alunos/turma. 
Tabela 2 - Desempenho dos tutores por fator/média por turma.

\begin{tabular}{|c|c|c|c|c|c|c|c|c|c|c|c|}
\hline \multicolumn{12}{|c|}{ Média por Turma } \\
\hline rmas & 0 & 1 & 2 & 3 & 4 & 5 & 6 & 7 & 8 & 9 & 10 \\
\hline \multicolumn{12}{|c|}{ Fatores de Estratégias Motivacionais } \\
\hline \multicolumn{12}{|c|}{ Turmas Tutores sem Curso EaD } \\
\hline A & $0 \%$ & $0 \%$ & $0 \%$ & $0 \%$ & $0 \%$ & $0 \%$ & $3,17 \%$ & $3,17 \%$ & $19,84 \%$ & $24,60 \%$ & $49,21 \%$ \\
\hline B & $0 \%$ & $0 \%$ & $5,05 \%$ & $0 \%$ & $1,01 \%$ & $11,11 \%$ & $8,08 \%$ & $11,11 \%$ & $23,23 \%$ & $29,29 \%$ & $11,11 \%$ \\
\hline $\mathrm{C} 2$ & $0 \%$ & $0 \%$ & $0 \%$ & $0 \%$ & $0 \%$ & $0 \%$ & $2,22 \%$ & $5,93 \%$ & $15,56 \%$ & $24,44 \%$ & $51,85 \%$ \\
\hline $\mathrm{G}$ & $0 \%$ & $0 \%$ & $0 \%$ & $0 \%$ & $0 \%$ & $0 \%$ & $3,47 \%$ & $4,17 \%$ & $12,50 \%$ & $17,36 \%$ & $62,50 \%$ \\
\hline \multicolumn{12}{|c|}{ Turmas Tutores com Curso EaD } \\
\hline $\mathrm{D}$ & $0 \%$ & $0 \%$ & $0 \%$ & $0 \%$ & $1,01 \%$ & $\mid 11,11 \%$ & $7,07 \%$ & $\mid 19,19 \%$ & $20,20 \%$ & $28,28 \%$ & $13,13 \%$ \\
\hline$E$ & $0 \%$ & $0 \%$ & $0 \%$ & $0,79 \%$ & $1,59 \%$ & $1,59 \%$ & $3,97 \%$ & $7,94 \%$ & $11,90 \%$ & $26,19 \%$ & $46,03 \%$ \\
\hline 12- & $0 \%$ & $0 \%$ & $0 \%$ & $0 \%$ & $0 \%$ & $0 \%$ & $0 \%$ & $1,39 \%$ & $9,72 \%$ & $12,50 \%$ & $76,39 \%$ \\
\hline $\mathrm{K}$ & $10,00 \%$ & $3,33 \%$ & $8,89 \%$ & $4,44 \%$ & $8,89 \%$ & $5,56 \%$ & $17,78 \%$ & $10,00 \%$ & $8,89 \%$ & $4,44 \%$ & $17,78 \%$ \\
\hline \multicolumn{12}{|c|}{ Respeito aos Alunos } \\
\hline \multicolumn{12}{|c|}{ Turmas Tutores sem Curso EaD } \\
\hline$A$ & $0 \%$ & $0 \%$ & $0 \%$ & $0 \%$ & $0 \%$ & \begin{tabular}{|l|}
$0 \%$ \\
\end{tabular} & $0 \%$ & $0 \%$ & $21,43 \%$ & $32,14 \%$ & $46,43 \%$ \\
\hline B & $0 \%$ & $0 \%$ & $0 \%$ & $0 \%$ & $0 \%$ & $4,55 \%$ & $9,09 \%$ & $13,64 \%$ & $9,09 \%$ & $18,18 \%$ & $45,45 \%$ \\
\hline $\mathrm{C} 2$ & $0 \%$ & $0 \%$ & $0 \%$ & $0 \%$ & $0 \%$ & $0 \%$ & $0 \%$ & $3,33 \%$ & $13,33 \%$ & $23,33 \%$ & $60,00 \%$ \\
\hline$G$ & $0 \%$ & $0 \%$ & $0 \%$ & $0 \%$ & $0 \%$ & $0 \%$ & $0 \%$ & $0 \%$ & $12,50 \%$ & $15,63 \%$ & $71,88 \%$ \\
\hline \multicolumn{12}{|c|}{ Turmas Tutores com Curso EaD } \\
\hline D & $0 \%$ & $0 \%$ & $0 \%$ & $0 \%$ & $0 \%$ & $9,09 \%$ & $0 \%$ & $18,18 \%$ & $22,73 \%$ & $31,82 \%$ & $18,18 \%$ \\
\hline $\mathrm{E}$ & $0 \%$ & $0 \%$ & $3,57 \%$ & $0 \%$ & $0 \%$ & $0 \%$ & $0 \%$ & $3,57 \%$ & $14,29 \%$ & $14,29 \%$ & $64,29 \%$ \\
\hline 12 & $0 \%$ & $0 \%$ & $0 \%$ & $0 \%$ & $0 \%$ & $0 \%$ & $0 \%$ & $0 \%$ & $12,50 \%$ & $18,75 \%$ & $68,75 \%$ \\
\hline $\mathrm{K}$ & $5,00 \%$ & $5,00 \%$ & $0 \%$ & $5,00 \%$ & $0 \%$ & $20,00 \%$ & $5,00 \%$ & $15,00 \%$ & $20,00 \%$ & $15,00 \%$ & $10,00 \%$ \\
\hline \multicolumn{12}{|c|}{ Desempenho Didático e Domínio do Conteúdo } \\
\hline \multicolumn{12}{|c|}{ Turmas Tutores sem Curso EaD } \\
\hline$A$ & $0 \%$ & $0 \%$ & $0 \%$ & $0 \%$ & $0 \%$ & $2,10 \%$ & $5,04 \%$ & $3,36 \%$ & $13,87 \%$ & $28,57 \%$ & $47,06 \%$ \\
\hline$B$ & $0 \%$ & $0,53 \%$ & $4,28 \%$ & $0 \%$ & $0,53 \%$ & $10,16 \%$ & $12,30 \%$ & $17,11 \%$ & $22,46 \%$ & $17,65 \%$ & $14,97 \%$ \\
\hline $\mathrm{C} 2$ & $0 \%$ & $0 \%$ & $0 \%$ & $0 \%$ & $0 \%$ & \begin{tabular}{|l|}
$0,39 \%$ \\
\end{tabular} & $1,57 \%$ & \begin{tabular}{|l|}
$1,96 \%$ \\
\end{tabular} & $14,12 \%$ & $25,10 \%$ & $56,86 \%$ \\
\hline$G$ & $0 \%$ & $0 \%$ & $0,37 \%$ & $0,74 \%$ & $0 \%$ & $\mid 0,37 \%$ & $0,37 \%$ & $1,47 \%$ & $15,07 \%$ & $25,74 \%$ & $55,88 \%$ \\
\hline \multicolumn{12}{|c|}{ Turmas Tutores com Curso EaD } \\
\hline $\mathrm{D}$ & $0,53 \%$ & $0 \%$ & $0 \%$ & $0 \%$ & $0,53 \%$ & $10,16 \%$ & $3,74 \%$ & $21,93 \%$ & $22,99 \%$ & $24,06 \%$ & $16,04 \%$ \\
\hline$E$ & $0 \%$ & $0 \%$ & $0 \%$ & $0 \%$ & $0 \%$ & $\mid 2,68 \%$ & $5,36 \%$ & \begin{tabular}{|l|}
$5,36 \%$ \\
\end{tabular} & $8,04 \%$ & $28,13 \%$ & $50,45 \%$ \\
\hline 12- & $0 \%$ & $0,37 \%$ & $0 \%$ & $0 \%$ & $0 \%$ & $0 \%$ & $0,37 \%$ & $0,37 \%$ & $15,07 \%$ & $18,75 \%$ & $65,07 \%$ \\
\hline $\mathrm{K}$ & $5,88 \%$ & $7,06 \%$ & $10,59 \%$ & $2,35 \%$ & $7,65 \%$ & $14,12 \%$ & $6,47 \%$ & $5,88 \%$ & $11,76 \%$ & $11,76 \%$ & $16,47 \%$ \\
\hline
\end{tabular}

Já a tabela 4 demonstra a nota média para cada tutor em cada um dos três fatores. Os dados foram apurados verificando a nota média de cada item dos 28 apresentados no questionário e com em seguida calculada a nota média de cada fator. 
Tabela 3 - Nota média por tutor/fator avaliado

\begin{tabular}{|l|c|c|c|c|c|c|c|c|}
\hline \multicolumn{7}{|c||}{ Nota Média Por Tutor/Fator Avaliado } \\
\hline \hline Turma / Fator & A & B & C2 & G & D & E & I2- & K \\
\hline Estratégias Motivacionais & 9,1 & 7,6 & 9,2 & 7,8 & 8,9 & 9,3 & 9,6 & 5,6 \\
\hline Respeito aos Alunos & 9,3 & 8,6 & 9,4 & 8,2 & 9,2 & 9,6 & 9,6 & 6,5 \\
\hline Didática e Conteúdo & 9,0 & 7,6 & 9,3 & 7,9 & 9,0 & 9,3 & 9,5 & 5,8 \\
\hline
\end{tabular}

O tutor melhor avaliado foi o da turma 12. Tanto nos fatores de estratégias motivacionais quanto nos fatores de desempenho didático e domínio do conteúdo o percentual das notas recebidas abaixo da nota 8 foi menor que $1,50 \%$, sendo de $1,39 \%$ e $0,74 \%$ respectivamente.

O desempenho mais próximo ao dele foi do tutor da turma $A$ que nos fatores estratégias motivacionais teve $6,34 \%$ das notas atribuídas abaixo da nota 8 e da turma C2 nos fatores de desempenho didático e domínio do conteúdo que teve apenas $3,92 \%$ das notas abaixo da nota 8.

Em relação à nota média os tutores $\mathrm{A}, \mathrm{C} 2, \mathrm{E}$ e $\mathrm{I} 2$ têm notas semelhantes e acima de 9,0. Nos fatores de respeito aos alunos o desempenho do tutor da turma $G$ foi praticamente o mesmo do desempenho do tutor da turma 12.

O tutor da turma 12 realizou o curso de formação de tutores - treinamento 2010/11. O programa do curso: conhecendo o EAD, fórum de notícias, fórum dos tutores, feedback de atividades, fórum da turma, atualização de perfil, mensagem individual, fórum de dúvidas. A reciclagem do treinamento é feita por meio de vídeoaulas.

Quanto aos demais tutores destacam-se o desempenho dos responsáveis pelas turmas A, C2, D e E. Os dois primeiros não possuem o curso de tutoria em EaD e os dois últimos possuem.

O desempenho que menos satisfação trouxe aos alunos foi da turma $\mathrm{K}$, cujo tutor apresenta o curso de tutoria. Destaca-se que nos fatores de estratégia motivacional $35 \%$ das notas ficou abaixo da nota 5 e nos fatores de desempenho didático e domínio do conteúdo $33,53 \%$ das notas está abaixo da nota 5 . 
Analisando os resultados da pesquisa podemos verificar que o desempenho dos tutores não depende do fato dele possuir ou não o curso de tutoria, pois enquanto a avaliação menos satisfatória foi de um tutor que possui o curso, outras duas avaliações excepcionais foram de profissionais que não possuem o curso.

Algumas questões sobre os tutores surgem que deveriam ser averiguadas em uma nova pesquisa com a finalidade de verificar o desempenho dos tutores em educação à distância via internet.

É fundamental conhecer os tutores para ter um melhor entendimento do resultado da pesquisa. Poderia ser por meio de um questionário ou entrevista, onde pudesse ser averiguado:

- ano de realização do curso de tutoria;

- programa do curso de tutoria;

- experiências anteriores em tutoria;

- período de duração destas experiências em tutoria;

- reciclagem do conhecimento/curso de tutoria;

- experiências como docente;

- período de duração das experiências como docente. 


\section{CONCLUSÃO}

Este presente trabalho tinha como objetivo identificar se o treinamento específico em tutoria é determinante no desempenho dos tutores no ensino à distância via internet.

Vimos com o resultado dos dados colhidos que somente a reação dos alunos ao desempenho dos tutores é insuficiente para responder à pergunta problema formulada: $O$ treinamento específico da tutoria em aD via internet é necessário para o exercício da tutoria?

Apesar de incontestável a necessidade de treinamento aos profissionais de qualquer área de atuação, novas variáveis devem ser investigadas, tais como: a prática após a realização do curso ou mesmo durante o curso; a experiência anterior ao curso; a experiência docente anterior ao curso, entre outras.

Além dos dados sobre os tutores, também enriqueceria os resultados a analise dos dados dos participantes. Com esses dados a pesquisa estaria englobando dados importantes na conclusão dos resultados e estes seriam mais acertivos quanto à realidade. 


\section{REFERÊNCIAS}

Belloni, Maria Luiza - Educação a Distância, Editora Autores Associados Corrêa, Juliane - Educação a Distância - Orientaçõs Metodológicas, Artmed, 2007.

Borges-Andrade, J E; Abbad, G; Mourão, L - Treinamento, Desenvolvimento e Educação em Organizações e Trabalho, Artmed, 2006.

Borges-Andrade, J. E. (2002). Desenvolvimento de Medidas em Avaliação de Treinamento. Estudos de Psicologia,

Souza, Carlos Alberto e Spanhol, Fernando José e Limas, Jeane Cristina de Oliveira e Cassol, Marlei Pereira - Tutoria na Educação a Distância.

Bomfin, David - Pedagogia no Treinamento - Correntes Pedagógicas no Ambiente de Aprendizagem nas Organizações - $2^{\mathrm{a}}$ Edição - Rio de Janeiro - Qualitymark, 2004.

Machado, Liliana Dias e Elian de Castro - O Papel da Tutoria em Ambientes de EAD - Universidade Federal do Ceará, 2004.

Costa, Rozalina Cássia de Andrade Ruas - O Tutor online na EAD: Perfil, Atribuições e Importância.

Benfatti, Eliana de F. S. S. e Stano, Rita de Cássia M. T. - A Professoralidade de uma tutoria em EaD Virtual - Ensino a Distância.

Santamarina, Anderson - Contextualização do Ensino na Modalidade EAD

Zerbini, Thaís - Estratégias de Aprendizagem, Reações aos Procedimentos de um Curso via Internet, Reações ao Tutor e Impacto do Treinamento no Trabalho. 
Borges-Ferreira, Maria Fernanda - Avaliação de Reações e Aprendizagem em Disciplinas de Curso Técnico Profissionalizante Oferecidas à Distância.

Júnior, Arnaldo O. Souza, Liana R. B. Cardoso, Cleidinalva M. B. Oliveira e Elis R. S. Oliveira - Prática Pedagógica em Cursos EaD: Relato de Experiência de Capacitação de Professores - Tutores do Programa da Universidade Aberta do Brasil no CEAD/UFPI.

Kenski, Vani Moreira - Perfil de Tutor de Cursos pela Internet do Sebrae - Site Educacional Ltda, São Paulo, SP.

Consulting, All - Estudo Setorial Ensino à Distância - Julho 2010. 


\section{Questionário de Avaliação de Reação do aluno ao Tutor}

Para responder as próximas questões, pense em seu tutor, em como ele respondia suas dúvidas, em como ele corrigia os exercícios. A escala abaixo varia de $\mathbf{0}$ (nunca) a 10 (sempre). Leia atentamente os itens listados e escolha o ponto da escala que melhor descreve a sua opinião sobre seu tutor. Registre sua resposta à direita de cada item. Por favor, não deixe questões em branco.

\begin{tabular}{|c|c|c|c|c|c|c|c|}
\hline Reação do aluno ao tutor & & 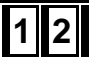 & \begin{tabular}{|l|l|l|}
3 & 4 \\
\end{tabular} & 56 & \begin{tabular}{l|l|l|l|}
7 & 8 \\
\end{tabular} & & 10 \\
\hline 1. Estimula a interação entre os alunos. & & & & & & & \\
\hline $\begin{array}{l}\text { 2. Encoraja os participantes a discutirem coletivamente suas dúvidas e } \\
\text { questionamentos. }\end{array}$ & & & & & & & \\
\hline 3. Envia mensagens de incentivo ao aluno. & & & & & & & \\
\hline 4. Utiliza expressões afetuosas ao se dirigir ao aluno. & & & & & & & \\
\hline 5. Elogia a participação dos alunos nas discussões. & & & & & & & \\
\hline 6. Faz críticas construtivas. & & & & & & & \\
\hline 7. Demonstra alegria com o sucesso do aluno. & & & & & & & \\
\hline 8. Está disponível nas horas marcadas. & & & & & & & \\
\hline 9. Responde rapidamente as consultas do aluno. & & & & & & & \\
\hline 10. Leva em consideração as idéias dos participantes. & & & & & & & \\
\hline 11. Demonstra bom humor durante a sua participação no curso. & & & & & & & \\
\hline 12. Elogia os participantes pelo desempenho no decorrer do curso. & & & & & & & \\
\hline 13. Utiliza sua experiência profissional ao orientar o aluno. & & & & & & & \\
\hline $\begin{array}{l}\text { 14. Demonstra segurança ao orientar o aluno sobre temas relacionados ao } \\
\text { curso. }\end{array}$ & & & & & & & \\
\hline 15. Fornece respostas que esclarecem as dúvidas do aluno. & & & & & & & \\
\hline 16. Utiliza linguagem de fácil compreensão. & & & & & & & \\
\hline 17. Participa ativamente das discussões dos alunos. & & & & & & & \\
\hline $\begin{array}{l}\text { 18. Utiliza adequadamente os recursos de interação disponibilizados pelo } \\
\text { curso. }\end{array}$ & & & & & & & \\
\hline $\begin{array}{l}\text { 19. Ressalta os benefícios práticos do curso nos contatos com os } \\
\text { participantes. }\end{array}$ & & & & & & & \\
\hline 20. Indica caminhos ao invés de dar respostas prontas. & & & & & & & \\
\hline 21. Comunica-se sem erros de português. & & & & & & & \\
\hline 22. Apresenta exemplos que ilustram bem o tema discutido. & & & & & & & \\
\hline $\begin{array}{l}\text { 23. Muda a forma de explicar até que os participantes compreendam os } \\
\text { assuntos do curso. }\end{array}$ & & & & & & & \\
\hline $\begin{array}{l}\text { 24. Aproveita os acertos dos participantes para enfatizar os aspectos mais } \\
\text { importantes do tema. }\end{array}$ & & & & & & & \\
\hline 25. Integra teoria e prática em suas explicações. & & & & & & & \\
\hline $\begin{array}{l}\text { 26. Direciona as discussões nos chats e fóruns, evitando conversas que } \\
\text { fujam do tema. }\end{array}$ & & & & & & & \\
\hline 27. Cria oportunidades para os participantes manifestarem suas idéias. & & & & & & & \\
\hline 28. Indica diversas fontes de pesquisa sobre os temas do curso. & & & & & & & \\
\hline
\end{tabular}

